\title{
Realidades Virtual e Aumentada: estratégias de Metodologias Ativas nas aulas sobre Meio Ambiente
}

\section{Virtual and Augmented Realities: strategy of Active Methodologies in classes about Environment}

\author{
CARMINO LÓPEZ GARCÍA \\ Universidade de Salamanca (USAL) - Espanha \\ CARLOS ALBERTO CATALINA ORTEGA \\ Instituto Tecnológico de Castilla y León (ITCL) - Espanha \\ HERIK ZEDNIK \\ Universidade Estadual do Ceará (UECE) - Ce/Brasil
}

\begin{abstract}
Resumo: Neste artigo, vamos aproximar o leitor das oportunidades e das vantagens de duas inovadoras tecnologias que estão se integrando ao contexto educacional: Realidade Virtual e Realidade Aumentada. O artigo aborda desde definições e características, com o objetivo de diferenciar cada tecnologia, até a apresentação de aplicativos no contexto da Educação Ambiental, com o objetivo de compartilhar com os professores novas estratégias que façam uso das metodologias ativas e novos recursos digitais. Abordaremos algumas experiências de uso dessas tecnologias aplicadas ao ensino/aprendizagem do Meio Ambiente e quais são as suas vantagens para a Educação.
\end{abstract}

Palavras-chave: Educação Ambiental. Realidade Aumentada. Realidade Virtual.

\begin{abstract}
In this article the reader will be closer to the opportunities and benefits of two innovative technologies which are integrating the educational context: Virtual Reality and Augmented Reality. The article not only discusses the definition and characteristics of such technologies in order to differentiate them, but it also presents applications in the context of Environmental Education, in order to share new strategies that make use of active methodologies and new digital resources with teachers. Some experiences with using these technologies applied to the Environment teaching and learning will be presented, as well as their benefits for education.
\end{abstract}

Keywords: Aumented Reality. Environmental Education. Virtual Reality 


\section{Introdução}

A Educação Ambiental está experimentando uma integração no currículo educativo, que vai além de tema transversal, como era considerada anteriormente. O motivo é a grande preocupação que existe em relação aos perigos da mudança climática, que é causada, dentre outros fatores, pelo processo de industrialização e pelo consumo desenfreado, principalmente nos países desenvolvidos. As mudanças pautadas na legislação, que procuram reduzir o impacto negativo das medidas ambientais, não são suficientes para impedir esta situação. Prova disso são as reuniões internacionais cada vez mais frequentes sobre alterações legislativas em cada país, com a finalidade de melhorar as ações de proteção e conservação ambiental. Por exemplo, a última destas cúpulas, para debater questões do Meio Ambiente, foi a de Paris (PLANELLES 2015). Estes acordos precisam de apoio na Educação, pois "[...] as atuais condições em que se desenvolve o mundo exigem mais fortemente a Educação Ambiental como uma via para formar as novas e futuras gerações" (GONZÁLEZ DÍAZ et al 2014, p. 11).

Realidades Virtual (RV) e Aumentada (RA) são duas das tecnologias mais inovadoras, atualmente, com potencial para atividades didáticas criativas e estimulantes. Cada vez mais, estão mais amplas e permitem vivenciar experiências únicas; proporcionam ao usuário uma grande interatividade. Presume-se que é o usuário quem tem o controle do que está fazendo e, portanto, pode aprender sobre o Meio Ambiente de uma forma prática. Ambas as Realidades possibilitam a exibição do conteúdo de forma diferente, atrativa e análoga ao real. Têm um impacto direto na motivação extrínseca do alunado de forma instantânea, já que seu aporte visual e interativo é surpreendente (ZAPATERO GUILLÉN 2012, p. 112, 114).

Promover atividades que estimulem o desejo dos alunos de aprender é muito importante. Nesse sentido, vale citar o que diz Pozo (2005, p. 110), quando afirma que "[...] não há cognição sem emoção". Um aluno motivado com conteúdos dinâmicos e interativos aprenderá e assimilará, muito melhor, os conceitos trabalhados.

Estas tecnologias trabalham diretamente criando experiências, o que facilita, assim, o desenvolvimento de competências, tão importantes, atualmente, no currículo educacional e no alcance de aprendizagens significativas. Em virtude das Realidades Virtual e Aumentada, os alunos podem ter experiências que, em seu próprio contexto, muito provavelmente, não seriam possíveis, por limitações econômicas ou físicas (viagens ao espaço, às profundezas dos oceanos, ao interior do corpo humano, por exemplo).

Neste trabalho, veremos duas tecnologias semelhantes, mas que se diferenciam em pontos específicos, Realidade Virtual e Realidade Aumentada, além de consubstanciarmos o uso em atividades de incentivo à aprendizagem sobre o Meio Ambiente.

Incluindo a Introdução, o artigo está organizado em sete seções. Nas seções 2 e 3, abordamse os conceitos e definições relativos às Realidades Virtual e Aumentada, respectivamente. Na seção 4, apresentam-se ferramentas de RV e RA aplicadas ao ensino/aprendizagem sobre Meio Ambiente. Na seção 5, debate-se a integração educacional das tecnologias de RV e RA. Na seção 6 , destacam-se as tecnologias de RV e RA como estratégia de Metologias Ativas. A seção 7 delineia as considerações finais, bem como sugestões para trabalhos futuros.

\section{Realidade Virtual: o que é e o que não é?}

A expressão Realidade Virtual foi inicialmente utilizada por Jaron Lanier, na década de 1980 , cujos estudos se voltavam para a indústria de simuladores multiusuários em ambiente compartilhado. Por ser um termo abrangente, "[...] acadêmicos, desenvolvedores de software e pesquisadores tendem a defini-lo com base em suas próprias experiências, gerando diversas definições na literatura" (NETTO; MACHADO; OLIVEIRA 2002, p.5). Para uma melhor compreensão, o Quadro 1 apresenta algumas das definições mais comuns de RV. 


\begin{tabular}{|l|l|}
\hline \multicolumn{1}{|c|}{ AUTOR } & \multicolumn{1}{c|}{ CONCEITO } \\
\hline Jaron Lanier [1980] & $\begin{array}{l}\text { Diferenciar simulações tradicionais feitas por computador de simulações, } \\
\text { envolvendo múltiplos usuários em um ambiente compartilhado. }\end{array}$ \\
\hline Manetta; Blade [1995] & $\begin{array}{l}\text { Um sistema de computador usado para criar um mundo artificial no qual o } \\
\text { usuário tem a impressão de estar e a capacidade de navegar e manipular } \\
\text { objetos nele. }\end{array}$ \\
\hline Roehl [1996] & $\begin{array}{l}\text { É uma simulação de um ambiente tridimensional gerado por computador, em } \\
\text { que o usuário é capaz tanto de ver quanto de manipular os conteúdos desse } \\
\text { ambiente. }\end{array}$ \\
\hline $\begin{array}{l}\text { Botella Arbona; Garcia- } \\
\text { Palacios; Baños Rivera; } \\
\text { Quero Castelhano [2007, } \\
\text { p.17] }\end{array}$ & $\begin{array}{l}\text { É uma tecnologia que permite a criação de um espaço tridimensional por meio } \\
\text { vantagem de que podemos introduzir, no ambiente virtual, elementos e } \\
\text { eventos que consideramos úteis, segundo o objetivo a que nos propomos. }\end{array}$ \\
\hline
\end{tabular}

Quadro1 -Definições de Realidade Virtual Fonte: Elaboração própria

Como podemos constatar, as definições têm vários elementos em comum, dentre estes, estar em um ambiente tridimensional criado por computador, ao qual temos a sensação de pertencer e com o qual podemos interatuar (OTERO FRANCO; FLORES GONZÁLEZ 2011, p 188-190). Na última referência, estão destacados os elementos mais importantes, na visão dos autores, para uma experiência de alta qualidade e com grande valor educativo: interações, eventos, conteúdos e ações simuladas são levantados para o fim específico a que nos propomos.

Ver a Amazônia, através de um modelo 3D, por exemplo, é interessante, mas não pode contribuir muito mais que a visualização de fotos ou documentários. No entanto, ver como a poluição afeta ambientes naturais, experimentar o que acontece em um vulcão, percorrer o rio Amazonas, com informações sobre cada planta e/ou animal da região, ou cuidar virtualmente de uma horta, contribuem de maneira significativa para a compreensão e a apropriação dos conceitos.

No setor educativo, as aplicações devem possibilitar diferentes metodologias de ensino, como apoio a professores e alunos, nos processos de ensino e aprendizagem. Nesse sentido, Zednik (2015) destaca a premência em expandir a perspectiva construcionistai, em que as práticas educativas explorem as novas tecnologias, considerando-as não apenas como uma nova ferramenta de apoio à aprendizagem:

[...] a ideia é que as escolas superem a fase de uso da tecnologia para modernização das práticas tradicionais e passem a potencializar as TIC nas atividades educacionais, ultrapassando a visão relativista de um recurso a mais, para explorar pedagogicamente o grande poder de interação, comunicação e colaboração que as Tecnologias Digitais e seus usuários podem desenvolver. (ZEDNIK, 2015, p. 160).

Para obter uma boa ferramenta educativa, é essencial construir equipes multidisciplinares, que complementem cada uma das partes envolvidas: uma forte equipe de professores e uma entidade com experiência no desenvolvimento técnico deste tipo de aplicações. Desse modo, é possível transladar a metodologia e os conteúdos, por meio de interações dentro do ambiente de Realidade Virtual aos alunos, de uma maneira criativa, atrativa e geradora de significados.

Além disso, é importante esclarecer que "[...] quando falamos de aprendizagem virtual em Educação, devemos saber diferenciar entre estes dois conceitos: ambientes virtuais e realidade virtual" (CATALINA ORTEGA; LOPEZ GARCIA, 2015, p. 93). Realidade Virtual não está relacionada ao sistema LMSii, mas a outra tecnologia muito diferente que explicaremos mais adiante. Em ambos os ambientes, a apropriação do conhecimento se dá por meio do virtual, mas não se trata da mesma tecnologia, tampouco do mesmo processo de aprendizagem. 


\section{Realidade Aumentada: o que é e como funciona?}

Primeiramente, tentaremos entender o que é Realidade Aumentada por meio da análise de duas das definições mais comuns: Milgram e Kishino (1994) e Ronald Azuma (1997). Milgram e Kishino (1994) definem a Realidade Aumentada como qualquer lugar entre as extremidades do virtuality continuum, em que o virtuality continuum se estende desde o completamente real até o completamente virtual. Podemos ver esse fenômeno mais claramente na Figura 1 - RealityVirtuality Continuum.

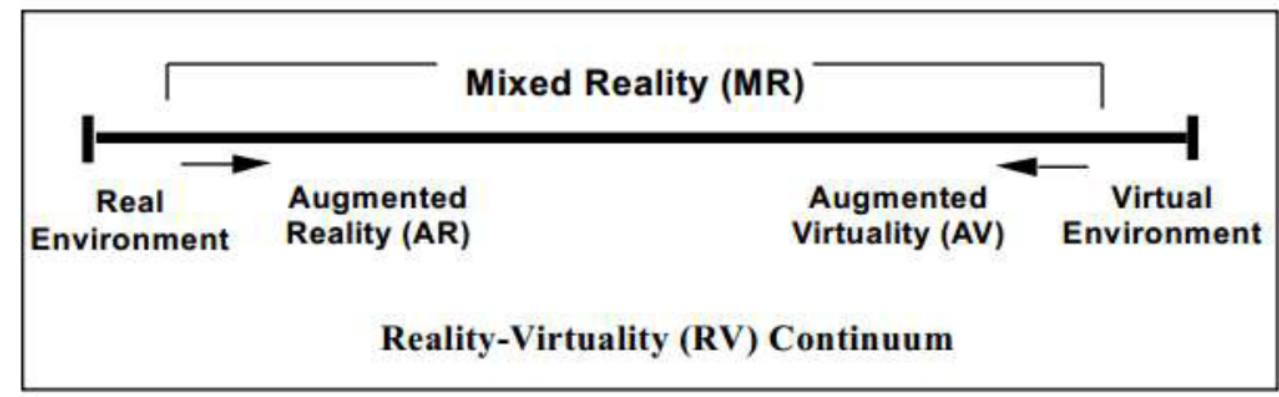

Figura 1 - Reality-Virtuality Continuum Fonte: Milgram e Kishino (1994)

Como podemos visualizar, na parte esquerda da Figura 1, temos o ambiente real e, na direita, temos os ambientes virtuais (que estariam incluídos na Realidade Virtual), tudo o que estiver entre esses dois mundos é considerado Realidade Mista. Esta inclui a Realidade Aumentada, em que adicionamos elementos virtuais à realidade, e a Virtualidade Aumentada, em que adicionamos elementos reais ao mundo virtual. A maneira mais comum de falar de todos estes conceitos é Realidade Aumentada e, portanto, assim o trataremos neste trabalho.

Azuma (1997), um pesquisador da Nokia Research Center Hollywood, Califórnia, definiu que um sistema de Realidade Aumentada é aquele que atende às seguintes características:

- combina elementos reais e virtuais;

- é interativo em tempo real;

- está registrado em 3D.

No início do uso da Realidade Aumentada na educação, existiu equívoco sobre o que é e o que não é Realidade Aumentada. A exemplo, trabalhava-se com os códigos $Q R$ Codes nas salas de aula, como se fossem Realidade Aumentada, quando, na realidade, não são:

"[...] os QR Codes são muitas vezes confundidos com códigos de realidade aumentada porque eles são visualmente semelhantes [...] mas o que os códigos QR fazem é codificar a informação, uma cadeia de texto, que normalmente é uma página web. Eles nos levam a esse lugar para nos dar informações adicionais. Em troca, os marcadores de Realidade Aumentada nos dão mais informações. Podemos obter a partir deles como estamos posicionados em relação à imagem para colocar o objeto 3D" (CATALINA ORTEGA, 2014b).

Essa tecnologia deverá ter grande impacto na Educação, pois possibilita novas maneiras de visualização, comunicação e interação com pessoas e conteúdos. Para ilustrar, a Figura 2 mostra a Realidade Aumentada aplicada: 


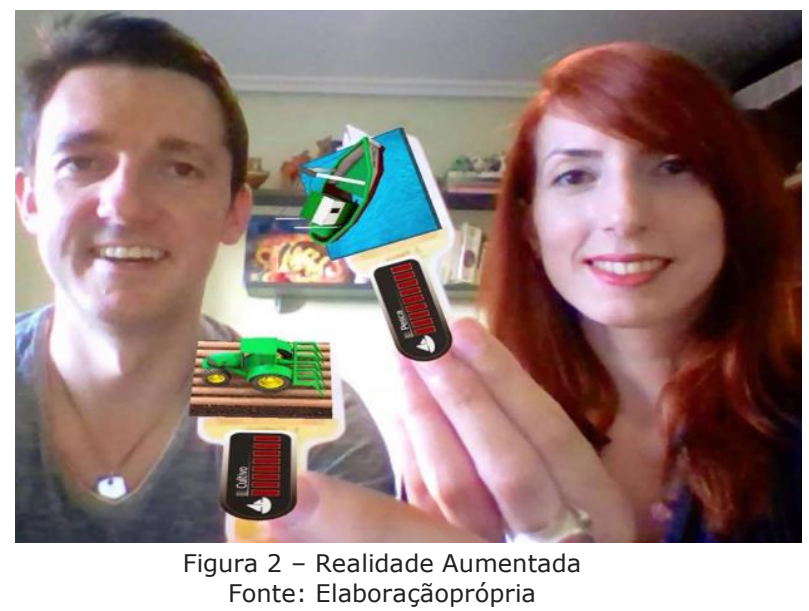

Atualmente, a forma mais difundida de uso da Realidade Aumentada é ter a imagem obtida a partir de um telefone com câmera ou de uma webcam, com a qual focamos um marcador (uma imagem ou um marcador típico com quadrados pretos e brancos) que nos permitirá ver, sobre este mesmo marcador, um objeto 3D. O que está realmente acontecendo (de forma simplificada) é o seguinte:

- O telefone ou o computador obtêm uma imagem da câmera que está conectada;

- A imagem é processada para encontrar um determinado marcador. Os marcadores são predefinidos no aplicativo e, de forma simplificada, podemos dizer que há um identificador único (por exemplo: ID $=17$ ) e conhecemos o seu tamanho no mundo real (por exemplo: Quadrado de $5 \mathrm{~cm}$ );

- Se o marcador é localizado, calcula-se onde se encontram as marcas em relação à posição do dispositivo móvel, isto é, seu deslocamento $(x, y, z)$ e a rotação relativa;

- Uma vez que temos esta informação em um ambiente 3D, a posição de uma câmera e um objeto 3D, podemos manipulá-los de acordo com a preferência do programador. Associamos o ID 17 com objeto 3D, texto, vídeo, áudio, dentre outros que queremos, e o colocamos na posição, na escala e na rotação desejadas;

- Uma vez com o objeto em seu lugar, podemos adicionar todas as interações ou animações que se queira, de modo que o usuário pressione uma tecla, um botão, aproxime outra marca, faça um gesto, neste caso, podendo-se visualizar uma nova interação.

Portanto, um sistema de Realidade Aumentada localiza uma referência no nosso ambiente real para posicionar objetos 3D. Se tivéssemos essa marca localizada, por exemplo, ao lado de uma impressora, poderíamos instruir o usuário a manusear ou consertar. Os objetos 3D não têm por que estar sobre as marcas, pois estas são apenas uma referência para unir o mundo virtual 3D com o mundo 3D real.

\section{Usos no ensino/aprendizagem sobre o Meio Ambiente}

Agora que sabemos as diferenças entre Realidade Virtual e Realidade Aumentada, dois conceitos que frequentemente são confundidos por suas similaridades, já podemos referenciar alguns dos aplicativos que são utilizados para estudar o Meio Ambiente por meio destas tecnologias. Lembremos que "[...] na Realidade Virtual substituímos o ambiente com elementos ou contextos baseados ou não em algo que exista, mas todo o conteúdo que vemos é gerado pelo computador. Na Realidade Aumentada, temos um ambiente real ao que acrescentamos informação virtual". (CATALINA ORTEGA, 2014a).

As ferramentas de RA e RV têm a capacidade de estimular visualmente o usuário, o que confere um potencial significativo para a aprendizagem. Nesse sentido, os alunos podem construir novos conhecimentos baseados em interações com os objetos de RV e RA, que 
possibilitam ao usuário uma experiência muito semelhante ao ambiente real, trazendo informações subjacentes à vida.

\subsection{Aplicações de Realidade Virtual e Realidade Aumentada para aprendizagem sobre o MeioAmbiente - Recursos existentes}

Atualmente, existem poucos aplicativos baseados na tecnologia da Realidade Virtual e na tecnologia da Realidade Aumentada, para estudar o Meio Ambiente. Nesta seção, relacionamos algumas das mais interessantes, nomeando e dando uma breve explicação sobre esses ambientes. A seguir, encontram-se listados abaixo.

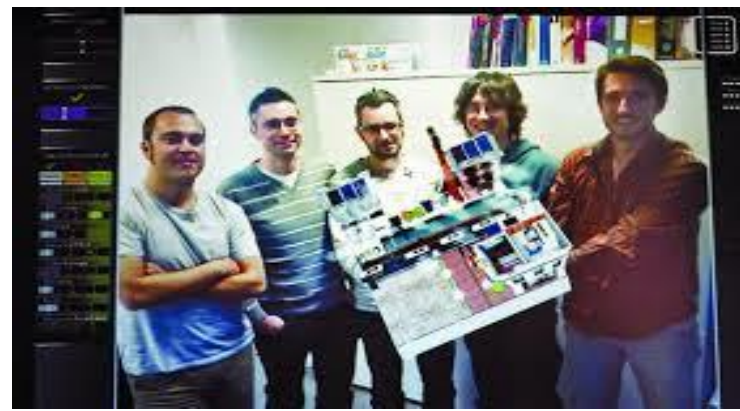

Figura 3- estARteco: Jogo com Realidade Aumentada para o equilíbrio dos ecossistemas. Espanha. Fonte: Catalina Ortega [2012]

a) estARteco: este é um jogo gratuito com RA para estudar o equilíbrio entre diferentes ecossistemas. Ele foi desenvolvido pela área de Realidade Virtual e Realidade Aumentada do Instituto Tecnológico de Castilla e Leon, Espanha (ITCL). Através de 4 níveis de jogo e 3 diferentes ecossistemas, os alunos poderão aprender sobre o equilíbrio entre as diferentes ações ambientais (CATALINA ORTEGA, 2012).

b) Aprendizagem dos animais: aplicativo da Universidade de Valladolid, Espanha. Usando um marcador de Realidade Aumentada Vuforia com editor Unity 3D, com a linguagem de programação JavaScript e SDK, eles construíram um parque zoológico, onde se visualizam cenas com animais (MARTÍNEZ ZARZUELA et al, n.d., p 75-76).

c) Conservação dos peixes: aplicativo de Realidade Aumentada que visa educar os bons hábitos de conservação dos peixes em Taiwan. Este é um jogo baseado em um livro enriquecido com Realidade Aumentada Imersiva (KOONGLIN; HSIEH; WANG; SIE; CHANG, 2011, p 181187).

d) Vistas de Realidade Virtual: no diplomado controle da poluição da Open University (OU), facilitam-se as visualizações de locais concretos, por meio de RV. Não é, neste caso, Realidade Virtual Imersiva (BURNLEY 2007, p. 1-15).

e) Astronomia Virtual em um Planetário: através de um ambiente simulado utilizando RV, visualiza-se um planetário através do qual as relações espaciais tridimensionais são facilitadas para o ensino de astronomia (YU et al 2015, p 33-50).

f) O Rio Conasauga: o Centro Business Media da Universidade de Tennessee Tech, em colaboração com o Instituto de Conservação do Aquário Tennessee (TNACI), utilizando Óculos Rift, recria o rio Conasuaga em Realidade Virtual, a partir de um campo de 360 graus de visualização (PRWEB, 2015).

g) O reservatório Feitsui em Taipei: por meio da Realidade Virtual, o governo Taipei criou, com modelos 3D, o ecossistema desta área para aprendizagem sobre o Meio Ambiental (TAIPEI, 2013).

A Educação Ambiental moderna propõe uma Pedagogia comprometida com a "[...] recuperação do sentido humano do espaço habitado, abrangendo tanto a dimensão biosférica quanto as dimensões socioinstitucionais e mentais" (MORAES 2000), a partir de "[...] uma didática específica para a Educação Ambiental, com base em um modelo de ensino estruturado nas perspectivas construtivista, complexa e crítica" (GARCIA 2015, p. 4). Esta perspectiva 
educativa nos dá as chaves para a abordagem tecnológica por meio da qual contribuem com seu desenvolvimento. Na verdade, as tecnologias de Realidade Aumentada e Realidade Virtual facilitam o desenvolvimento deste modelo pedagógico. Além disso, podemos "[...] conseguir uma comunicação multissensorial eficaz na sala de aula, observando que os alunos têm diferentes capacidades de aprendizagem" (GONZÁLEZ ASPERA; CHÁVEZ HERNANDEZ 2011, p 123).

\subsection{Possibilidades atuais na aprendizagem: do mais simples ao mais complexo}

Conhecer e interagir com o ambiente natural propicia aos estudantes o desenvolvimento do conhecimento e do respeito a si mesmos, a construção da cultura da sustentabilidade e da razoabilidade, de uma cultura que valorize a vida, que promova o equilíbrio dinâmico e harmônico entre seres viventes e não viventes. Uma das vantagens que a Realidade Virtual pode proporcionar é a recriação do Meio Ambiente no modo virtual, especialmente aqueles locais que estão muito longe do lugar onde estamos, ou com difícil acesso. Assim, somos capazes de percorrer a Amazônia, o interior de um vulcão, os desertos, imergir no fundo do mar, andar em território lunar. E tudo isso sem expor os alunos aos perigos e aos impactos econômicos que todo este processo resultaria na vida real. Assim, "[...] parece que a chave não está tanto na capacidade de imersão, mas na interatividade com o Meio Ambiente. De fato, em algumas profissões é quase a única maneira de educar, como o caso da formação de pilotos de aviação" (CATALINA ORTEGA; LOPEZ GARCIA, 2015, p. 94).

As possibilidades são enormes quando combinamos ambientes de visualização com camadas de informação adicional e interatividade. Para ilustrar este ponto, apresentamos uma série de exemplos (em formato de subtópicos, a fim de didatizarmos a apresentação aqui proposta) muito interessantes sobre aprendizagem do Meio Ambiente, utilizando essas tecnologias.

\section{a) Aprendizagem em mundos submarinos}

Um dos exemplos mais recentes deste tipo de aplicação (embora planejada para outros fins) é a impressionante demonstração do recente capacete de Realidade Aumentada HTC Vive. A demonstração nos move a um galeão no mar, onde podemos ver diferentes tipos de vida marinha.
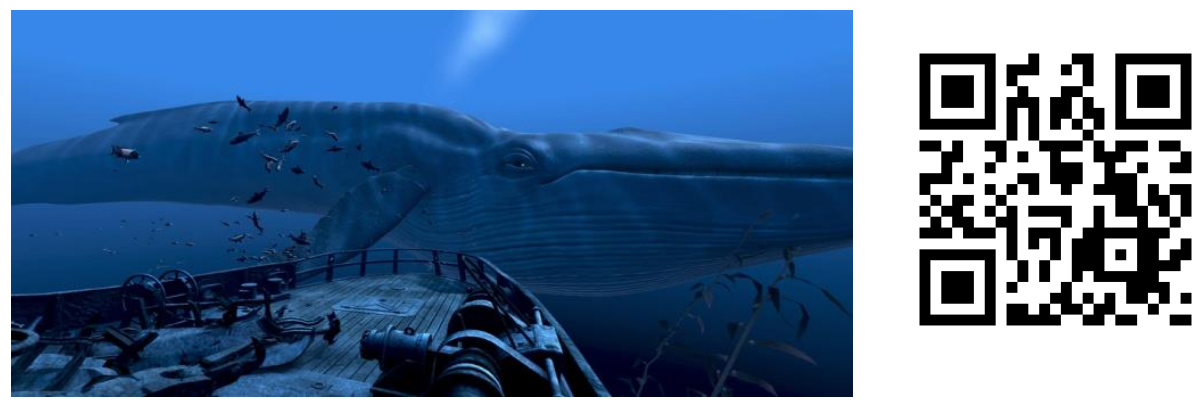

Figura 4 - Demonstração de HTC Vive The Blue ${ }^{\mathrm{i} i}$ Fonte: Canal YouTube da HTC Vive

A qualidade gráfica e o realismo do show são enormes, uma vez que o aplicativo é projetado para mostrar todas as capacidades destes dispositivos. Imagine adicionar camadas que podem ser ativadas para ver os nomes e as propriedades de cada animal que estamos vendo. Poderíamos, até mesmo, segui-los, para compreender a sua maneira de nadar, o modo como respiram, visualizá-los de forma transparente para estudar sua anatomia interna, além de reconhecer as plantas no fundo do oceano. Não nos esqueçamos de que estamos em um mundo virtual, ou seja, podemos nos mover livremente, sem necessitarmos de um tanque de oxigênio. 


\section{b) Aprender na fazenda}

Este segundo aplicativo foi concebido para um público de jovens das séries iniciais. $\mathrm{Na}$ atualidade, muitas pessoas das grandes cidades desconhecem a vida do campo, inclusive de onde vêm os alimentos que comemos todos os dias. O aplicativo trata de conhecer como é uma fazenda, sem a necessidade de organizar uma visita extraclasse a esse lugar, evitando-se custos e tempo de viagem, além da responsabilidade inerente ao acompanhamento de menores de idade.

Para realizar atividades relacionadas a este tema, podemos fazer uso das duas tecnologias:

- Realidade Virtual: podemos usar um GoogleCardboariv ou similar, que nos permita ver como é uma fazenda e como se produzem alguns dos alimentos nela.

- Realidade Aumentada: talvez a escolha desta tecnologia seja uma das melhores opções neste caso, uma vez que os óculos de Realidade Virtual de qualquer tipo podem não ser totalmente confortáveis para as crianças. Em vez disso, por meio da Realidade Aumentada, podemos utilizar uma tela grande e focar a câmera para uma mesa onde as crianças poderiam colocar os marcadores de Realidade Aumentada. Sobre cada marcador apareceria um animal e poderiam ser visualizadas informações sobre ele.

Para adicionar mais interação ou mais jogo ao aplicativo, podemos fazer com que diferentes marcadores interajam uns com os outros. Como exemplo, se o marcador da vaca e a forragem se aproximam, poderíamos visualizar a vaca se deslocando de uma marca a outra, até que ela conseguisse comer sua desejada forragem.

\section{c) National Geographic}

A National Geographic e a BBC montaram apresentações em Realidade Aumentada para recordarmos o maravilhoso mundo em que vivemos.
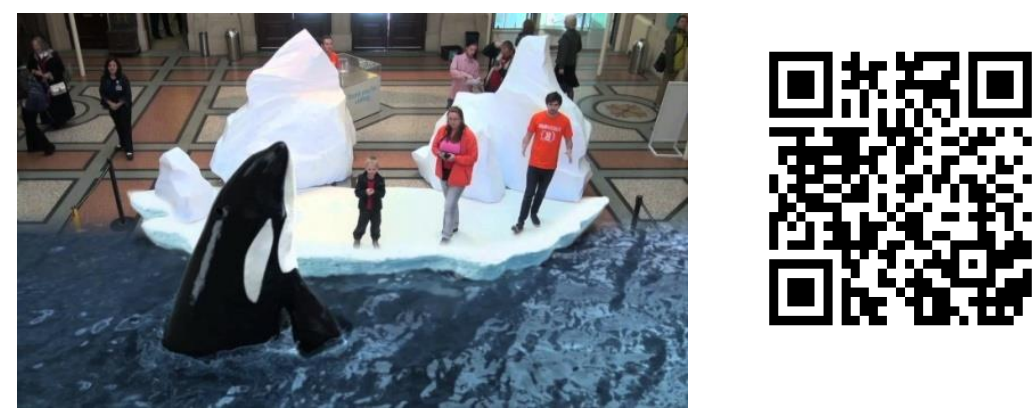

Figura 5 - Interativode Realidade Aumentada da National Geographic - grandes espaços Fonte: Canal YouTube National Geographic

O objetivo, neste caso, é compreender conceitos gerais, a partir de atividades interativas, já que permanecem, mais significativamente, na memória dos alunos, pois eles são os protagonistas.

\section{d) Óculos Social VR}

A conferência do Facebook de 2016 apresentou uma interessante interação chamada "Óculos Social VR", em que duas equipes utilizavam Óculos Rift em locais diferentes. Esta demonstração permite-nos compreender as possibilidades de aplicação desta tecnologia. 

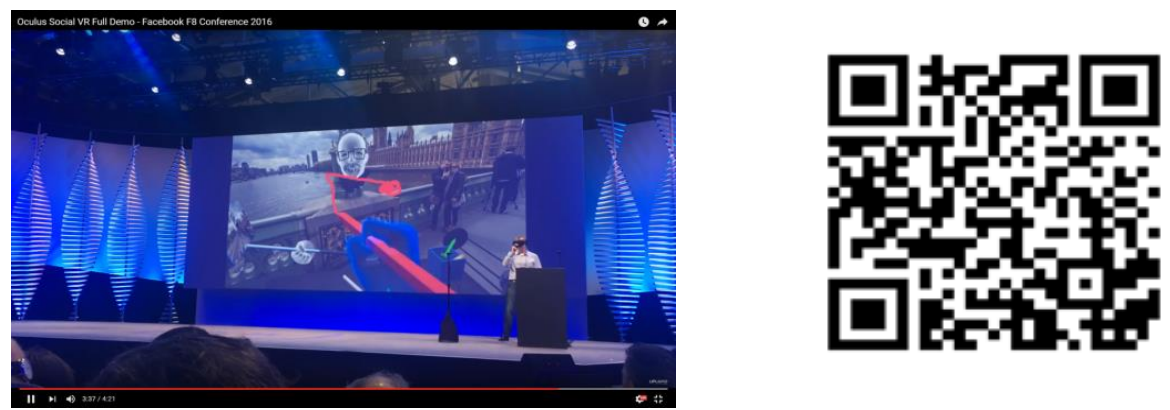

Figura 6 - Demo 2016 conferência do Facebook.

Fonte: Canal YouTube da Facebook conference 2016

\section{Integração educacional dessas tecnologias}

A integração das TIC na educação requer a consideração de várias questões. Nunca deve ser proposta como um exercício de ensino por meio da tecnologia sem, antes, uma abordagem do contexto educacional em que se pretende integrar, do ponto de vista educacional, as características específicas dos alunos. Assim, as TIC devem estar direcionadas na formação dos educandos, levando-se em consideração, ainda, o modo como esta ferramenta digital irá influenciar a sua aprendizagem.

Para alcançarmos um nível mais adequado de integração das várias aplicações de Realidade Virtual e Realidade Aumentada que vimos até agora, devemos ter, em mente, uma série de variáveis. Para os professores, de um modo geral, que queiram utilizar-se dessas duas tecnologias, em sua prática educativa, apresentamos algumas recomendações que fornecemos tanto do ponto de vista da teoria quanto de nossa própria experiência profissional (CABEROALMENARA, 2010):

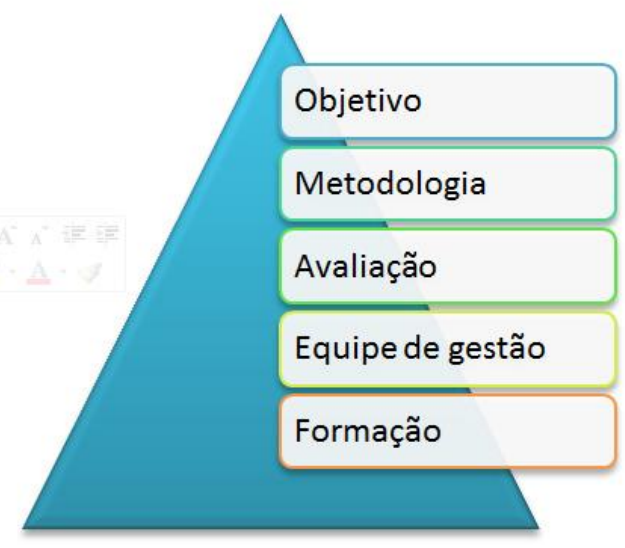

Figura 7 - Integração educativa de aplicações de RV e RA Fonte: Elaboração própria

10. A integração de aplicações de Realidades Aumentada e Virtual colabora na aprendizagem visual, desde que mantenha o objetivo específico do conteúdo. Se 0 professor busca que seus alunos compreendam um conceito particularmente complexo, o mais sensato seria procurar uma aplicação cujo conteúdo específico fosse apresentado por meio de estímulos visuais. Se não focar o estímulo visual no conteúdo específico (OBJETIVO), a apresentação, com diversos recursos audiovisuais e muitas aplicações podem distrair os alunos para outros itens que estão sendo vistos, dificultando a concentração e a aprendizagem on-line, mesmo que a apresentação seja atraente. Eles aprendem, com certeza, mas não especificamente sobre o que o professor está buscando focar durante aquele momento da aula. 
20. A segunda consideração que fazemos está focada na metodologia. Essas tecnologias trazem muitos elementos de base audiovisual, visual e interativa. Esses elementos devem ser ativos, para serem integrados, com sucesso, as metodologias de sala de aula. Podem ser usados tanto nas atividades de ensino presencial e e-learning, quanto no modo de blended learning. No entanto, cada um terá de estudar as características da ferramenta específica para aplicar educacionalmente. Assim, sabemos, em primeira mão, como o aluno acessa a ferramenta, para que o professor possa determinar a melhor maneira de observar a aprendizagem que irá desenvolver durante o uso.

30. Esta situação leva-nos a considerar a avaliação. Só se consegue aprender quando essas tecnologias estão diretamente ligadas às habilidades de trabalho e ao desenvolvimento das Inteligências Múltiplas. Isto significa que a aprendizagem só pode ser pensada se relacionada ao desenvolvimento de aptidões, em vez da memorização do conteúdo. Esta situação determina, diretamente, o tipo de ferramenta de avaliação a ser utilizado para valorizar a aprendizagem desenvolvida pelo aluno, e será essencial para considerar o tempo em que deve ser aplicada. Recomendamos a utilização de sistemas de avaliação ligados à observação da atividade do estudante enquanto estiver usando determinada tecnologia, ou por meio da observação de um exercício prático em que deve aplicar os conhecimentos adquiridos durante a experiência com Realidade Aumentada e Realidade Virtual.

40. O apoio da equipe de gestão é fundamental. Na maioria dos casos, quando um professor tenta integrar novas tecnologias tão marcantes, em sua sala de aula, como no caso de Realidade Virtual e Realidade Aumentada, geralmente é exigido pela direção da escola uma justificativa do ponto de vista educacional para tal empreendimento pedagógico. A formação de professores, nessa área, é crucial, para que seja capaz de criar um projeto cuja justificativa teórica seja suficiente para assegurar o bom uso da tecnologia para a educação. Além disso, a escola deve permitir, em atividades educacionais, o uso de smartphones em sala de aula, uma prática ainda pouco permitida.

50. E já que estamos falando sobre a formação de professores, gostaríamos de enfatizar que, para alcançar uma utilização otimizada dos diferentes dispositivos e aplicativos necessários para o uso da Realidade Aumentada e Realidade Virtual, na sala de aula, é necessária uma formação prévia de professores. Um professor que não domina o uso de um tablet, um computador ou um smartphone, ou de óculos de realidade necessita de formação para tirar o máximo proveito dessas tecnologias. Nem todos os professores desenvolveram o hábito de autoaprendizagem.

De todas as recomendações dadas até agora, concentremo-nos, especialmente, na escolha da metodologia adequada para uma abordagem didática que essas tecnologias exigem.

\section{Metodologias apropriadas para o uso de Realidade Virtual e Realidade Aumentada na educação}

A escolha certa de uma metodologia, para trabalhar com aplicações de Realidade Virtual e Realidade Aumentada, é crucial para o aluno retirar o máximo dessas ferramentas digitais. Para o treinamento de habilidades, o professor tem de escolher entre diferentes métodos dentro da ampla gama de metodologias ativas (TRISTAN, 2015). Isso irá garantir o dinamismo necessário que eles trazem para a experiência educacional com estas ferramentas.

No entanto, é importante considerar o tipo de aplicação que nós usamos, em sala de aula, para tomar essa decisão. Nem todos os aplicativos de Realidade Virtual e Realidade Aumentada são iguais, por exemplo, correspondem às características de um jogo sério, como é o caso estARteco; outros, porém, não facilitam experiências imersivas interativas, como o National Geographic; outros são, contudo, um atrativo a mais, como no caso dos Óculos VR; e muitos 
outros, que, na realidade, mostram 3D ou elementos em 2D, como ocorre no uso do aplicativo Aprendizagem dos Animais. Grande parte não permite interatividade colaborativa e deve ser empregada individualmente; outras exigem uma dinâmica gamificada, como em Serious Game.

Nesse sentido, tanto o objetivo educacional a ser alcançado, como a dinâmica da sala de aula, devem ser confrontados com as características das ferramentas digitais empregadas. A seleção adequada da ferramenta colabora com os processos de ensino e aprendizagem, potencializando o uso do material e delimitando seus limites e possibilidades (ZEDNIK et al, 2015). Para fazer uma escolha mais adequada da ferramenta, os professores podem fazer uso da Matriz de Decisão TDE, proposta por Zednik et al (2015) no artigo Matriz de Decisão das Tecnologias Digitais na Educação (TDE): Planejando Uma Aula Tecnopedagógica. A matriz permite aos professores conhecer e examinar ferramentas individuais e determinar quais ferramentas atendem às necessidades de ensino, previamente planejadas. A finalidade da Matriz de Decisão TDE, portanto, "[...] é ajudar na escolha da ferramenta mais apropriada para cada ação didática, juntamente com uma ampla discussão sobre os fatores que devem ser considerados tais como acessibilidade, requisitos técnicos e pedagógicos" (ZEDNIK, et al, 2015, p. 199).

Nesse contexto, além de saber selecionar a ferramenta que melhor atenda a necessidade docente/discente, é importante fazer uso de metodologias as quais o aluno seja sujeito ativo no processo ensino/aprendizagem. Há muitas metodologias ativas que podem ser interessantes de serem aplicadas na sala de aula, acompanhada por estas tecnologias de RV e RA.

Entre os modos mais comumente usados hoje, podemos destacar:

- Trabalho Colaborativo

- Flipped Classroom

- Aprendizagem baseada em projeto

- Aprendizagem Baseada em Problemas - PBL

- Aprendizagem baseada na reflexão sobre a experiência

- Gamification

- Mapas Conceituais - MC

- Just-In-Time Teaching - JiTT

- Estudos de Caso

- Instrução por Pares - PI

- Jogos Pedagógicos

- Design Thinking

Destacamos o estARteco como o mais recomendado para uso educacional em sala de aula. Ele permite a combinação de várias metodologias ativas, sem ser tão complexo. Para tanto, o professor deverá criar equipes, no caso da metodologia de trabalho colaborativo; fazer vídeos que explicam as variáveis do jogo sério para o Flipped Classroom; criar a estrutura da ABP para trabalhar em um Projeto de Aprendizagem Baseada ou integrar um sistema; trabalhar com a gamificação.

No entanto, em qualquer caso, antes de integrar qualquer aplicativo de Realidade Aumentada e Realidade Virtual, na sala de aula, recomenda-se ver o conhecimento prévio dos alunos em relação aos conceitos trabalhados no uso dessas ferramentas digitais. Se o professor perceber que os alunos não dominam as tecnologias, pode criar um plano de formação específica para os alunos, procurando sempre integrá-los nas metodologias ativas.

\section{Considerações Finais}

Ao longo deste artigo, compartilhamos conhecimentos acerca das tecnologias de Realidade Virtual e Realidade Aumentada. Nesse sentido, mostramos as diferenças entre elas e suas aplicações na Educação Ambiental, para uma compreensão maior dos conceitos aqui elencados. Também abordamos a ideia das Metodologias Ativas como estratégia essencial no desenvolvimento de atividades que objetivem o protagonismo do aluno enquanto ser autônomo, viabilizando a aprendizagem significativa acerca do Meio Ambiente e, consequentemente, proporcionando maior desenvolvimento da consciência ambiental. 
Para a integração adequada dessas tecnologias na Educação, é essencial considerarmos tanto contextos educacionais, tais como o tipo de conteúdo a ser trabalhado, quanto o nível de desenvolvimento da competência digital de professores e alunos (OTERO FRANCO; FLORES GONZÁLEZ, 2011, p 209-210). Nunca devemos perder a perspectiva de que estas tecnologias "[...] são recursos educativos, e não como tem acontecido com outras tecnologias que foram apresentadas como a panaceia que poderiam resolver os problemas educacionais" (CABERO; BARROSO, 2016, p. 51). É indiscutível que as tecnologias de RV e RA estão em consonância com a nova Educação Ambiental, baseada no desenvolvimento de competências, a partir da vivência de experiências em primeira pessoa e aprendizagem ubíqua.

'Papert [1985] chamou de construcionista sua proposta de utilização do computador, considerado uma ferramenta para a realização do conhecimento e para o desenvolvimento do aluno.

iiLMS- Learning Management System (Softwares para o gerenciamento de bancos de dados complexos).

iiipara visualizar o vídeo é necessário instalar um leitor de QR Codes no aparelho móvel. Existem diversos leitores de QR Codes gratuitos disponíveis na Internet (Barcode Scanner, QR Code Reader, QR Droid, TapMedia QR Reader), mas sugerimos o i-nigma.

ivhttps://vr.google.com/cardboard/

\section{Referências}

AZUMA, R. T. A Survey of Augmented Reality. Presence: Teleoperators and Virtual Environments, 1997, p.355-385.

BURNLEY, S. J. The use of virtual reality technology in teaching environmental engineering. Open Research Online. Retrieved from, 2007. Disponível em:

<http://www.tandfonline.com/doi/full/10.11120/ened.2007.02020002\#.VzfFmvmLSUk>

CABERO-ALMENARA, J. Los retos de la integración de las TICs en los procesos educativos: Límites y posibilidades. Perspectiva educacional, 2010, p. 32-61.

CABERO, J.; BARROSO, J. The educational possibilities of Augmented Reality. New approaches in educational research, 2016, p. 46-52. Disponível em: <http://naerjournal.ua.es/article/view/v5n1-7>.

CATALINA ORTEGA, C. A. estARteco: un juego formativo gratuito con realidad aumentada. CYLDigital., 2012, p. 18-19. Disponível em: <http://goo.gl/mZmly]>.

CATAlinA ORTEGA, C. A. Entrevista a Carlos Catalina. Proyecto RadioEDUBU. 2014 b. Disponível em: <http://www.ivoox.com/entrevista-a-carlos-catalina-audios-mp3_rf_3837987_1.html>.

CATALINA ORTEGA, C. A. Aplicaciones de Realidad Aumentada para formación y educación. Paper presented at Realidad Virtual y Realidad Aumentada. Aplicaciones tecnológicas al servicio de la formación. 2014. Disponível em: <http://www.innovarioja.tv/index.php/video/ver/1095>.

CATALINA ORTEGA, C. A.; LÓPEZ GARCÍA, C. La integración de la Realidad Virtual en educación: un reto por alcanzar. Revista Comunicación y Pedagogía. Monográfico Realidad Virtual y Educación., 2015, p. 287288, 92-98. Retrievedfromhttps://www.centrocp.com/comunicacion-y-pedagogia-287-288-realidad-virtualy-educacion/.

GONZÁLEZ ASPERA, A. L.; CHÁVEZ HERNÁNDEZ, G. La realidad virtual inmersiva en ambientes inteligentes de aprendizaje -Un caso en la educación superior. Revista ICONO14. Revista científica de Comunicación y Tecnologías emergentes, 9(2), 2011, 122-137. Disponível em:

<http://www.icono14.net/ojs/index.php/icono14/article/view/42> 
GONZÁLEZ DÍAZ, E.; ORAMAS FERNÁNDEZ, N.; GUTIÉRREZ TABOADA, R. Educación ambiental. Una vía para el desarrollo sostenible en las nuevas y futuras generaciones, Pedagogía y Sociedad. Cuba., 2014, p. 11-19. Disponível em: <http://revistas.uniss.edu.cu/index.php/pedagogia-y-sociedad/article/view/197>.

HERNÁNDEZ, N.; GONZÁLEZ, M.; MUÑOZ, P. La planificación del aprendizaje colaborativo en entornos colaborativos. Comunicar, 2014, p. 25-33.

KOONG LIN, H. C.; HSIEH, M. C.; WANG, C. H.; SIE, Z. Y.; CHANG, S. H. Establishment and usability evaluation of an interactive AR learning system on conservation of fish. TOJET: The Turkish Online Journal of Educational Technology, 2011, p. 181-187. Disponível em: http://files.eric.ed.gov/fulltext/EJ946626.pdf.

MANETTA, C.; BLADE. R. Glossary of Virtual Reality Terminology, International Journal of Virtual Reality, 1995, p. 35-39.

MARTÍNEZ ZARZUELA, M.; DÍAZPERNAS, F. J.; BARROSO MARTÍNEZ, L.; GONZÁLEZ ORTEGA, D.; ANTÓN RODRÍGUEZ, M. Mobile Serious Game using Augmented Reality for Supporting Children's Learning about Animals, International Conference on Virtual and Augmented Reality in Education. Abstract Book VARE 2013: Introducing Virtual Technologies in the classroom. 2013. Disponível em: <http://udv.ull.es/vare/data/vare2013_ID_58_short\%20PAPER.pdf>

MILGRAM, P.; KISHINO, F. A taxonomy of mixed reality visual displays, IEICE Transactions on Information Systems, Campinas: Papirus, 1997. Disponível em: <http://etclab.mie.utoronto.ca/people/paul_dir/IEICE94/ieice.htmIMORAES, Maria C. O Paradigma educacional emergente>

MORAES, M. C. O Paradigma educacional emergente. Campinas: Papirus, 1997.

NETTO, A. V.; MACHADO, LILIANE DOS S. E OLIVEIRA, M. C. F. DE. Realidade Virtual - Definições, Dispositivos e Aplicações", 2002. Disponível em: <http://www.di.ufpb.br/liliane/publicacoes/2002_reic.pdfAcessado em 14 de julho de 2016>.

OTERO FRANCO, A.; FLORES GONZÁLEZ, J. Realidad virtual: un medio de comunicación de contenidos. Aplicación como herramienta educativa y factores de diseño e implantación en museos y espacios públicos. Revista de comunicación y tecnologías emergentes, 2011, p. 185-211disponível em:

<http://icono14.net/ojs/index.php/icono14/article/viewArticle/28>

PLANELLES, M. La Cumbre de París cierra un acuerdo histórico contra el cambio climático. El País. 2015. Disponível em:

<http://internacional.elpais.com/internacional/2015/12/12/actualidad/1449910910_209267.html>

POZO, J. I. Aquisição de conhecimento, Artmed, Porto Alegre, 2015.

PRWEB. New Wave of Environmental Education Using Oculus Rift Virtual Reality. 2015 [prweb]. Disponível em: <http://www.prweb.com/releases/2015/04/prweb12677696.htm>

ROEHL, B. Special Edition Using VRML, USA: Mc Millan Computer Publishers. 1996. Disponivel em: <http://deby.net/FILES/e-books/(Ebook\%20-\%20Pdf)\%20Special\%20Edition\%20Using\%20Vrml.pdf>

TAIPEI. Virtual and Augmented Reality Systems in the Research and Development of the Feitsui Reservoir Environmental Education Module. 2013. Disponível em: Taipei. Yearbook 2013 website: <http://www.gov.taipei/ct.asp?xItem $=81143072 \&$ ctNode $=73800 \& \mathrm{mp}=100103>$

TRISTÁN, M. Las unidades formativas mediante metodologías activas. Aprendizaje basado en proyectos. 2015. Disponível em: <http://www.slideshare.net/slideshow/embed_code/44695702>

YU, K. C.; SAHAMI, K.; SAHAMI, V.; SESSIONS, L. C. Using a Digital Planetarium for teching seasons to undergraduates". Journal of Astronomy \& Earth Sciences Education (JAESE), 2015, p. 33-50. Disponível em: <http://www.cluteinstitute.com/ojs/index.php/JAESE/article/view/9276> 
ZAPATERO G. D. Aplicaciones didácticas de la realidad virtual al museo pedagógico de arte infantile. (Doctoral dissertation, Universidad Complutense de Madrid, Madrid, España), 2007. Disponível em: <http://biblioteca.ucm.es/tesis/bba/ucm-t29925.pdf>

ZEDNIK, H. e-Maturity: Gestão da Tecnologia numa Perspectiva de Melhoria do Desempenho Pedagógico. Universidade Federal do Rio Grande do Sul, Centro de Estudos Interdisciplinares em Novas Tecnologias na Educação, Programa de Pós Graduação em Informática na Educação, Porto Alegre, 2015. 318 f. Tese de doutorado.

ZEDNIK, H. et al. Matriz de decisão das tecnologias digitais na educação (TDE): planejando uma aula tecnopedagógica In: IX International Conference on Engineering and Computer Education - ICECE'2015, 2015, Zilina/ Slovakia. Technology Education for the Future: from simple Growth to Sustainable Quality of Living. São Paulo: COPEC, 2015. v.9.

Submetido para avaliação em 15 de Janeiro de 2017 Aprovado para publicação em 22 de março de 2017

\section{Camino López García}

Universidade de Salamanca -USAL - Espanha, camino_lopez@usal.es.

Carlos Alberto Catalina Ortega

Instituto Tecnológico de Castilla y León - ITCL - Espanha, carlos.catalina@itcl.es

Herik Zednik

Universidade Estadual do Ceará - UECE -Brasil, herik.zednik@ufrgs.br 